Editorials

\title{
Fuel Crisis vis-à-vis Green Fuel
}

\author{
Susmita Kamila, Ph D \\ Bhubaneswar, Odisha, India
}

The real sense of crisis often leads to bring some changes for betterment of society. We are in an age, where every day we are facing the crisis of energy. Decisions on current energy as well as fuel crisis in right direction can bring about a better, more sustainable future for our planet. We have huge opportunities and scope for innovative research and discoveries towards a more sustainable lifestyle. The requirement to modify the present energy model is at the top priority and is accepted as a mainstream business issue too.

When it comes to fossil fuels, it suggests somewhat of very old with a prehistoric impression due to its usage from very ancient times as back as Iron Age. However, the wide-scale extraction has been started due to the result of Industrial Revolution. The present form of such fuel probably took millions and millions of years to become so. But in a very short span of time- say approximately just 200 odd years- it has been consumed an incredible part forever. The report says- the oil reserves will vanish very soon based on the current rate of consumption and the oil deposit will be gone by 2052 even there won't be any change in population growth and aspiration. However, there are also certain arguments on the coal deposits, which can help to run the show with its adverse effect till 2088. Based on the increasing standard of living with the world's population, the fossil fuel might run out much earlier than the predicted time.

\section{So Now the Big Question for the Planet - Does the Show Run upto 2088 and beyond that the whole World will be Run out of Fossil Fuels?}

Obviously, the simple answer to this is NO. Some new reserves might be found out in between to extend this deadline slightly forward, though would be significantly smaller in size than the previous ones. So the only alternative would be obviously- renewables.

To overcome this fuel crisis, scientists have come up with innovative ideas to get alternate to fossil fuels as bio-fuels, using plants and animal origin to get biodiesel. Similarly, using ethanol, originated from various agricultural sources such as from corn, cereals, sugar cane etc to get blended gasohol or power alcohol to name a few. However, the major effect of such biofuels boon is the - increasing cost of foodstuff. But the

advanced technology focus on non-food sources such as landfill materials, wood and inedible plant parts for the production of certain biofuels. This not only helps in cutting down the use of fossil fuels but also recycling an enormous part of the waste effectively.

In addition to these, a different form of synthetic fuel has been formulated from green algae and popularly known as green fuel. These small blue - green algae are the kind of bacteria known as cyanobacteria, with relatively simple primitive life forms and surprisingly, this simple form of life could able to solve the world's big fuel crisis. This miracle happened in the laboratory of Biochemist Dan Robertson's at Life Sciences Square in Cambridge, Massachusetts.

For the culture of these little life forms, sunlight, saline water along with little fertilizers and carbon dioxide are needed without any farmland of course. On the other hand, these algae are surprisingly productive and a hectare of desert land filled with algae vats can produce biofuel per unit of biomass approximately eight times than the corn grown for fuel purpose. Besides, the positive aspects of this algaculture are the utilization of saline water without any additional farmland and fresh water. Apart from, the major advantages are to utilize both waste $\mathrm{CO}_{2}$ and wastewater as nutrient for the algal growth and moreover the fuel is inherently renewable.

But on the other way round, there are also few limitations like algal growth require controlled temperature condition, phosphorous as fertilizers, which is becoming scare. And lastly, this needs relatively high upfront capital cost. But, however, in comparison with others, these fuels certainly have the potential to replace a significant portion of the total fuel used in today's scenario.

California-based firm Sapphire Energy is already started producing crude oil using algae. This firm transformed desert areas into fertile, energy-producing land. The production of green algal fuel is not only limited to Sapphire Energy but most of the other developed and developing countries including India also started doing enormous research on it. The first tests of this green fuel have already been conducted in automobiles as well as in aircrafts successfully. Moreover, the innovators have already admit about the usage of green fuel, which will likely take a while longer. Even, at some point of time monotonous things still stand in the way of the green revolution. 